\title{
EPSL
}

Earth and Planetary Science Letters 160 (1998) 391-402

\section{Shallow bias of paleomagnetic inclinations in the Paleozoic and Precambrian}

\author{
D.V. Kent ${ }^{\mathrm{a}, *}$, M.A. Smethurst ${ }^{\mathrm{b}}$ \\ ${ }^{a}$ Lamont-Doherty Earth Observatory, Palisades, NY 10964, USA \\ ${ }^{b}$ Geological Survey of Norway, N-7040 Trondheim, Norway
}

Received 22 January 1998; revised version received 5 May 1998; accepted 7 May 1998

\begin{abstract}
An updated analysis of the global paleomagnetic database shows that the frequency distributions of paleomagnetic inclinations for the Cenozoic and Mesozoic eras (younger than $250 \mathrm{Ma}$ ) are compatible with a random geographical sampling of a time-averaged geomagnetic field that closely resembles that of a geocentric axial dipole. In contrast, the frequency distributions of paleomagnetic inclinations for the Paleozoic and Precambrian eras (prior to $250 \mathrm{Ma}$ ) are over-represented by shallow inclinations. After discounting obvious secondary causes for the bias, such as from data averaging, sedimentary inclination error, inhomogeneous lithological distributions, and tropical remagnetization, we show that the anomalous inclination distributions for the Paleozoic and Precambrian can be explained by a geomagnetic field source model which includes a relatively modest $(\sim 25 \%)$ contribution to the axial dipole from a zonal octupole field and an arbitrary zonal quadrupolar contribution. The apparent change by around 250 Ma to a much more axial dipolar field geometry might be due to the stabilization of the geodynamo from growth of the inner core to some critical threshold size, a gross speculation which would imply that either the threshold size was rather large or the inner core nucleated rather late in Earth history. Alternatively, if a geocentric axial dipole model is assumed or can eventually be demonstrated independently, the anomalous inclination distributions for the Paleozoic and Precambrian may reflect a tendency of continental lithosphere to be cycled into the equatorial belt, perhaps because geoid highs associated with long-term continental aggregates influence true polar wander. (c) 1998 Elsevier Science B.V. All rights reserved.
\end{abstract}

Keywords: paleomagnetism; dynamos; dipole-dipole methods; polar wandering; Phanerozoic; Precambrian

\section{Introduction}

A working model of the time-averaged geomagnetic field as that of a geocentric axial dipole (GAD) has proven to be an enormously successful and powerful hypothesis in paleomagnetism and is the simplest and most testable field configuration [1]. Strong

* Corresponding author. Tel.: +1 (914) 365-8544; Fax: +1 (914) 365-8158; E-mail: dvk@1deo.columbia.edu empirical support for the GAD hypothesis comes from analyses of the time-averaged paleomagnetic field for the most recent $5 \mathrm{Myr}$, a time interval represented by abundant, relatively uncomplicated data from globally distributed and well located geographical sites. Such studies show that the GAD model is a very good approximation to the observations; the only persistent departures from the axial dipole $\left(g_{1}^{0}\right)$ that can be adequately resolved tend to be small $(\sim 5 \%)$ contributions from zonal non- 
dipole (quadrupole, $g_{2}^{0}$, and perhaps octupole, $g_{3}^{0}$ ) fields (e.g., [2]). The strongly zonal character of the time-averaged field is not unexpected given the importance of westward drift in the secular variation [3] and means that the geometry of the time-averaged field can be delineated using only magnetic inclination data.

Geomagnetic field models become increasingly less well constrained for older epochs [4,5], but the broad success of paleomagnetic studies in describing plate motions (e.g., [6]) and accounting for the geographical distribution of paleoclimate indicators [711] strongly suggests that the GAD was a dominant feature of the time-averaged geomagnetic field over at least much of the Phanerozoic, or the past $550 \mathrm{Ma}$. For the preceding and much longer Precambrian Era, the GAD model is used virtually by default because the lower density of good quality data, the ambiguity of paleocontinental reconstructions (e.g., [1214]) and the often uncertain latitudinal significance of what few paleoclimate indicators are available (e.g., [15-17]) severely limit our ability to entertain alternative paleofield models. However, recent theoretical work shows that the Earth's inner core plays an important role in the dynamo process $[18,19]$ and yet it may conceivably not have formed until late in Earth's history [20]. The possibility that the fundamental generating conditions of the geomagnetic field have varied over geological time provides additional motivation to test the GAD hypothesis by some technique that is not dependent on specific paleoclimatological or paleogeographical interpretations.

Evans [21] used the frequency distribution of paleomagnetic inclinations to test the dipolar nature of the geomagnetic field over the Phanerozoic. Here, we conduct a similar test using an updated catalog of global paleomagnetic results for the Phanerozoic as well as the Precambrian. After consideration of possible systematic artifacts, we show that a marked change in paleomagnetic inclination distributions since the Paleozoic can be modeled by a decrease in non-dipole field (NDF) contributions to the GAD and speculate that this might be due to the stabilizing effects on the geodynamo of a growing inner core. Alternatively, the shallow bias in paleomagnetic inclinations in the Precambrian and Paleozoic could imply that the continents preferentially cycled through low-latitude positions, triggering or triggered by episodes of true polar wander.

\section{Analysis of paleomagnetic inclinations}

Evans showed that for any given zonal multipole field there is a distinctive frequency distribution of magnetic inclination $(I)$ for a set of observations made at randomly dispersed geographic sites. The expected frequency distributions of $I$ can be readily obtained by calculating $I$ in fixed intervals of $\cos (\theta)$, where $\theta$ is colatitude, to account for the latitudinal dependence of surface area on the globe. We used 0.001 increments of $\cos (\theta)$ for $\theta$ between $0^{\circ}$ and $180^{\circ}$ to generate 2001 values of $I$ whose latitudinal dependence for any combination of axial dipole, quadrupole or octupole can be obtained from the relationship:

$$
\begin{aligned}
& \tan (I)=\left\{2 \cos \theta+G 2\left[(9 / 2) \cos ^{2} \theta-(3 / 2)\right]\right. \\
& \left.\quad+G 3\left(10 \cos ^{3} \theta-6 \cos \theta\right)\right\} \\
& \quad \times\{\sin \theta+G 2(3 \sin \theta \cos \theta) \\
& \left.\quad+G 3\left[(15 / 2) \sin \theta \cos ^{2} \theta-(3 / 2) \sin \theta\right]\right\}^{-1}
\end{aligned}
$$

where $G 2=g_{2}^{0} / g_{1}^{0}$ and $G 3=g_{3}^{0} / g_{1}^{0}[2,22]$. Representing each inclination by its absolute value, $|I|$, so that data of normal and reversed polarity and/or from the Northern and Southern Hemisphere can be combined, and sorting the calculated values of $|I|$ in $10^{\circ}$ class intervals, we can obtain the same frequency distribution for an axial dipole (i.e., for $G 2=0$ and $G 3=0$ ) as shown by Evans [21]. This characteristic frequency distribution, where $|I|$ has a mean of $46.5^{\circ}$, a peak or mode in the range of $60^{\circ}-70^{\circ}$ and very low frequencies between $80^{\circ}-90^{\circ}$, corresponds to the GAD model and serves as the null hypothesis for testing observed paleomagnetic inclination distributions.

We analyzed 6419 mean inclinations from rock units ranging in age from $3500 \mathrm{Ma}$ to Recent that were compiled in an updated global paleomagnetic database (GPMDB v. 3.1; [23]). The compilation includes mean paleomagnetic directions for individual rock units so that the mean inclinations we use in the analysis will already represent some time-averaging of the geomagnetic field. The reliability of 
the data is undoubtedly very heterogeneous but a uniform quality evaluation or grading of the entire database is not yet available. From the overall total of 7569 entries in the database, we chose to exclude only results described by the authors of the studies as representing secondary magnetizations. This liberal acceptance criterion has the practical benefit of allowing a large data inventory in which the very poor data would contribute mainly noise to the analysis. Of greater concern are systematic errors introduced by data that are even seemingly adequate; fortunately, the importance of such tendencies in the database can be modeled and evaluated statistically, as described below.

Sampling distributions for the Cenozoic (0-65 Ma; $n=1536$ inclinations), Mesozoic (65-250 Ma; $n=1791)$, Paleozoic $(250-550 \mathrm{Ma} ; n=1815)$ and Precambrian (550-3500 Ma; $n=1277)$ are shown in Fig. 1. Even though the chosen time intervals vary widely in duration, they correspond to the main subdivisions of Earth history according to eras and also happen to contain subequal numbers of data points for the analysis. The corresponding frequency distributions of $|I|$ for these time intervals are shown in Fig. 2a. The main feature is that the distributions for the Paleozoic and Precambrian are noticeably skewed to lower $|I|$ values compared to the Cenozoic and Mesozoic. For example, mean $|I|$ are only $31^{\circ}$ and $37^{\circ}$ for the Paleozoic and Precambrian, respectively, and $49^{\circ}$ and $46^{\circ}$ for the Cenozoic and Mesozoic, respectively. None of the distributions, however, closely resembles the curve for the GAD model.

To minimize bias from spatiotemporal concentrations of sampling, the absolute values of the cataloged inclinations were averaged within $10^{\circ} \times 10^{\circ}$ latitude/longitude areas for eleven geologic periods in the Phanerozoic (Neogene, Paleogene, Cretaceous, ... , Ordovician, Cambrian) and in 50-Ma intervals in the Precambrian. The technique and its rationale are the same as advanced by Evans [21] with the result that there are fewer but more evenly distributed data points. The binned data were then grouped to construct frequency distributions of $|I|$ corresponding again to the Cenozoic $(n=253$ binned inclinations), Mesozoic $(n=342)$, Paleozoic $(n=352)$ and Precambrian $(n=531)$. There are 1478 binned values in all, or about one-quarter of the 6419 discrete inclination results. The Phanerozoic (Cenozoic, Mesozoic and Paleozoic combined) is represented by 5142 inclination values in 947 spatiotemporal bins, considerably greater than the 1271 inclination values in 430 bins available to Evans [21] in his analysis of approximately the same time interval. The Precambrian was not included in the analysis by Evans [21] but happens to be represented here by a larger number of binned data than the other eras because the very long duration of the Precambrian compensates for the fewer individual studies. Piper and Grant [24] used a population of 4787 inclination values for the Phanerozoic and Precambrian but did not bin the data in their analysis.

For the binned data, the Cenozoic and Mesozoic $|I|$ distributions closely resemble the GAD model (Fig. 2b). A $\chi^{2}$ test yields values of 3.63 and 7.18 for the Cenozoic and Mesozoic, respectively, which are much lower than the critical $\chi^{2}=15.51$ (eight degrees of freedom, $P=0.05$ ), indicating that there is indeed no good statistical reason to reject the hypothesis that the observed Cenozoic and Mesozoic distributions conform to the predicted GAD distribution. Evidently the large number of geographically dispersed data compensated for the relatively short amount of time available for plate motion in the Cenozoic and Mesozoic to produce a random paleogeographical sampling of inclinations. The Paleozoic and Precambrian $|I|$ distributions of binned data, however, still look decidedly skewed toward lower values compared to the Cenozoic and Mesozoic, as well as to the GAD model. For example, inclinations less than $30^{\circ}$ constitute $48 \%$ of the Paleozoic and $40 \%$ of Precambrian $|I|$ values compared to only $28 \%$ for the GAD model, $24 \%$ for the Cenozoic and $19 \%$ for the Mesozoic. The results of $\chi^{2}$ tests yielding values of 32.23 for the Paleozoic and 20.39 for the Precambrian distributions confirm that these distributions differ significantly from expectations of the GAD model.

\section{Sampling and recorder artifacts}

The anomalous $|I|$ distributions for the Paleozoic and the Precambrian may simply be artifacts of sampling bias or magnetic recording processes. One might argue, for example, that with increas- 

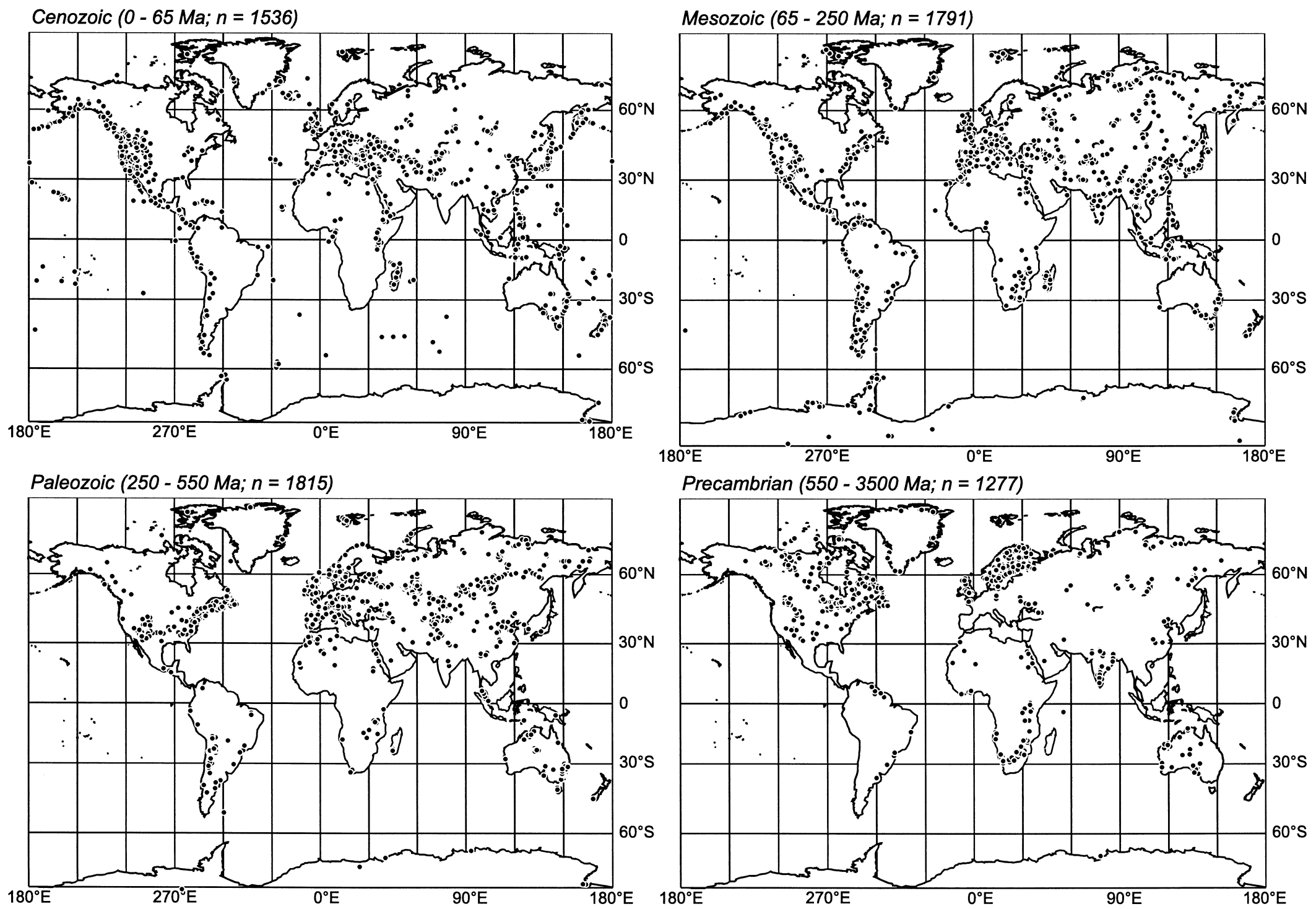

Fig. 1. Geographic distributions of sampling sites extracted from the Global Paleomagnetic Database v3.1 for the Cenozoic $(0-65$ Ma; $n=1536$ inclinations $)$, the Mesozoic (65-250 Ma; $n=1791)$, the Paleozoic (250-550 Ma; $n=1815)$, and the Precambrian (550-3500 Ma; $n=1277)$. 

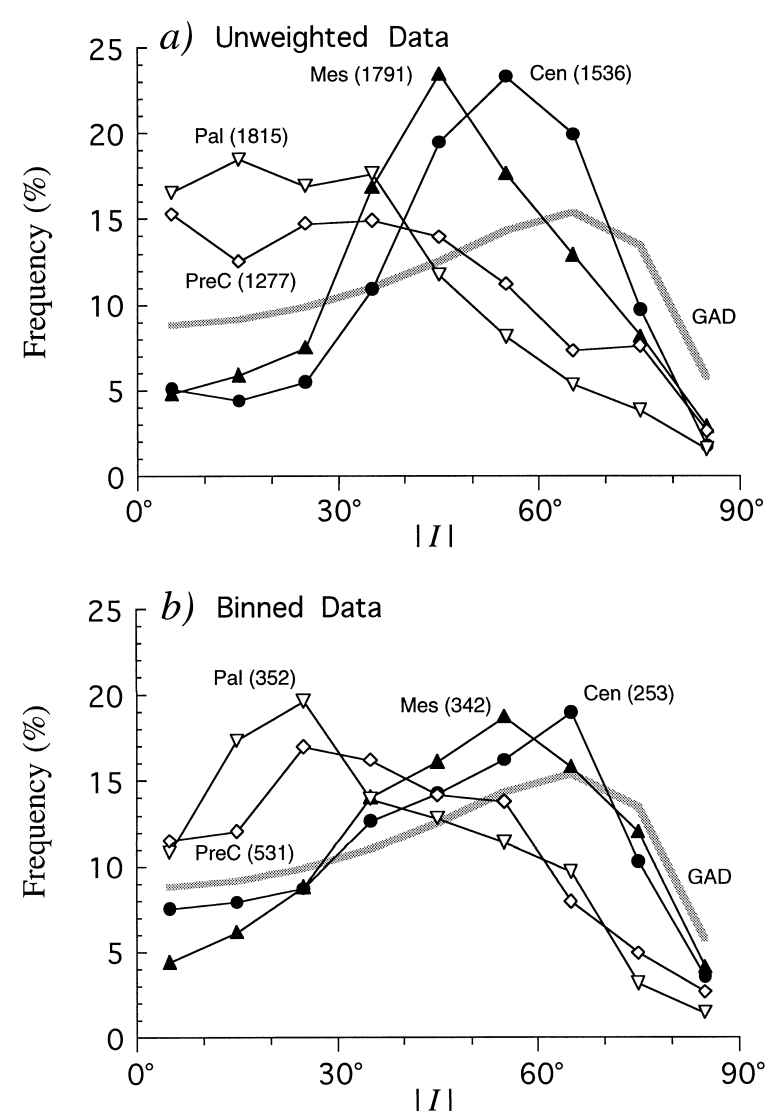

Fig. 2. Frequency distributions of $|I|$ for the Cenozoic, Mesozoic, Paleozoic, and Precambrian, compared to predicted $|I|$ distribution for GAD shown as heavy line. (a) Raw unweighted data with number of $|I|$ values for each era in parentheses. (b) Data binned by averaging in $10^{\circ}$ by $10^{\circ}$ latitude/longitude areas and the eleven geologic periods for the Cenozoic, Mesozoic and Paleozoic and 50-Ma time intervals for the Precambrian. Number of binned $|I|$ values for each era in parentheses.

ing geologic age, the $10^{\circ}$ by $10^{\circ}$ latitude/longitude grids are more likely to lump together results from far-traveled terrains, or that greater uncertainties in age assignments might result in the averaging of temporally distant results in the $\sim 50$-Ma intervals. Without attempting to address the specifics of potential sources of averaging bias, we note that the $|I|$ distributions for the Cenozoic and Mesozoic differ from the Paleozoic and Precambrian using either binned (i.e., spatiotemporally weighted or averaged) or individual data (Fig. 2). The obvious effect of spatiotemporal binning on the Cenozoic and Mesozoic data in bringing these $|I|$ distributions closer to the expected GAD pattern does indicate that the averaging procedure successfully reduces bias due to concentrated sampling.

Plate motions over the long durations of the Paleozoic and especially the Precambrian should help to produce a random (paleo)geographical sampling. However, most of the paleomagnetic data for the Paleozoic were obtained from Eurasia and North America (Fig. 1c), regions which tended to occupy low paleolatitudes in the Paleozoic according to independent lithofacies indicators of paleoclimate (e.g., [25]). An anomalous distribution of $|I|$ for the Paleozoic was described previously by Piper and Grant [24] and attributed to extensive remagnetizations in the late Paleozoic. These would exacerbate the potential for a sampling bias but the pattern could also be explained by the use of unweighted inclination data in their analysis. In any case, Eurasia and North America are also the source for much of the available global Precambrian paleomagnetic data (Fig. 1d) which have been interpreted to include evidence for rapid apparent polar wander including drift of these tectonic elements to regions with steep inclinations $[15,26]$. Thus while sampling bias may possibly contribute to the anomalous $|I|$ distribution for the Paleozoic, this is not an obvious explanation to account for a similarly anomalous $|I|$ distribution for the Precambrian.

Contamination by younger magnetizations also does not seem to provide an obvious explanation for the bias to shallow inclinations in the Precambrian (and Paleozoic) because the overprinting might be expected to produce frequency distributions more similar to the GAD-like patterns of the Mesozoic and Cenozoic. As an extreme example, we calculated that if all the sampling sites had been remagnetized in the present geomagnetic field, the resulting inclination distributions for all four (Cenozoic to Precambrian) data sets would in fact closely resemble the distribution for a GAD model.

Alternatively, the anomalous $|I|$ distributions for the Paleozoic and the Precambrian may be due to the prevalence of secondary shallowing of paleomagnetic inclinations during deposition or subsequent compaction of sediments. Inclination error in sediments has long been known from laboratory deposition experiments to follow King's Rule [27,28] which describes the remanent inclination, $I_{\mathrm{r}}$, as a 
function of the applied field inclination, $I_{\mathrm{a}}$, according to the relationship:

$\tan \left(I_{\mathrm{r}}\right)=f * \tan \left(I_{\mathrm{a}}\right)$

where the flattening factor, $f$, can vary from 0 (total shallowing) to 1 (no shallowing). King's Rule is applicable to a variety of models for depositional remanent magnetization (see review by Tauxe [29]) and also seems to describe the shallowing effect of compaction [30,31]. The frequency distributions of $|I|$ for a GAD model affected by different values of flattening factor are shown in Fig. 3a. Values of $f$ of about 0.5 to 0.6 produce shifts to shallower inclinations similar to those observed for the Paleozoic and Precambrian inclination data. However, although inclination shallowing corresponding to such values of $f$ has been observed in laboratory redeposition experiments in a variety of sediments [29], the prevalence of significant inclination shallowing in nature has been difficult to document and generally thought to be not important [32-34].

To assess the possible influence of inclination shallowing on the present results, we compared $|I|$ distributions for sedimentary rocks with those for crystalline rocks (igneous intrusives, igneous extrusives, and metamorphics). If sedimentary inclination shallowing was important, the $|I|$ distribution for sedimentary rocks should be more skewed to lower inclination values than for crystalline rocks in the same age category. The mean $|I|$ for sedimentary rocks is actually a few degrees steeper than for crystalline rocks in the Cenozoic $\left(47.3^{\circ}\right.$ vs. $\left.45.8^{\circ}\right)$, but is relatively shallower in the Mesozoic $\left(44.2^{\circ}\right.$ vs. $\left.50.3^{\circ}\right)$ as well as in the Paleozoic $\left(32.7^{\circ}\right.$ vs. $\left.35.6^{\circ}\right)$ and Precambrian $\left(31.5^{\circ}\right.$ vs. $\left.39.5^{\circ}\right)$. Of the four age categories, the Paleozoic data set has the largest number of data from sedimentary rocks $(n=1112$ inclination values in 282 bins) relative to crystalline rocks ( $n=703$ inclination values in 172 bins), yet the inclination distributions for crystalline and sedimentary rocks are virtually the same for unbinned data (Fig. 3b) even though the binned data are somewhat noisy and difficult to compare (Fig. 3c). On the other hand, the Precambrian has the largest proportion of data from crystalline rocks $(n=388$ bins) relative to sedimentary rocks ( $n=190$ bins), even though it shares with the Paleozoic an overall $|I|$ distribution skewed to lower inclinations. We therefore suggest
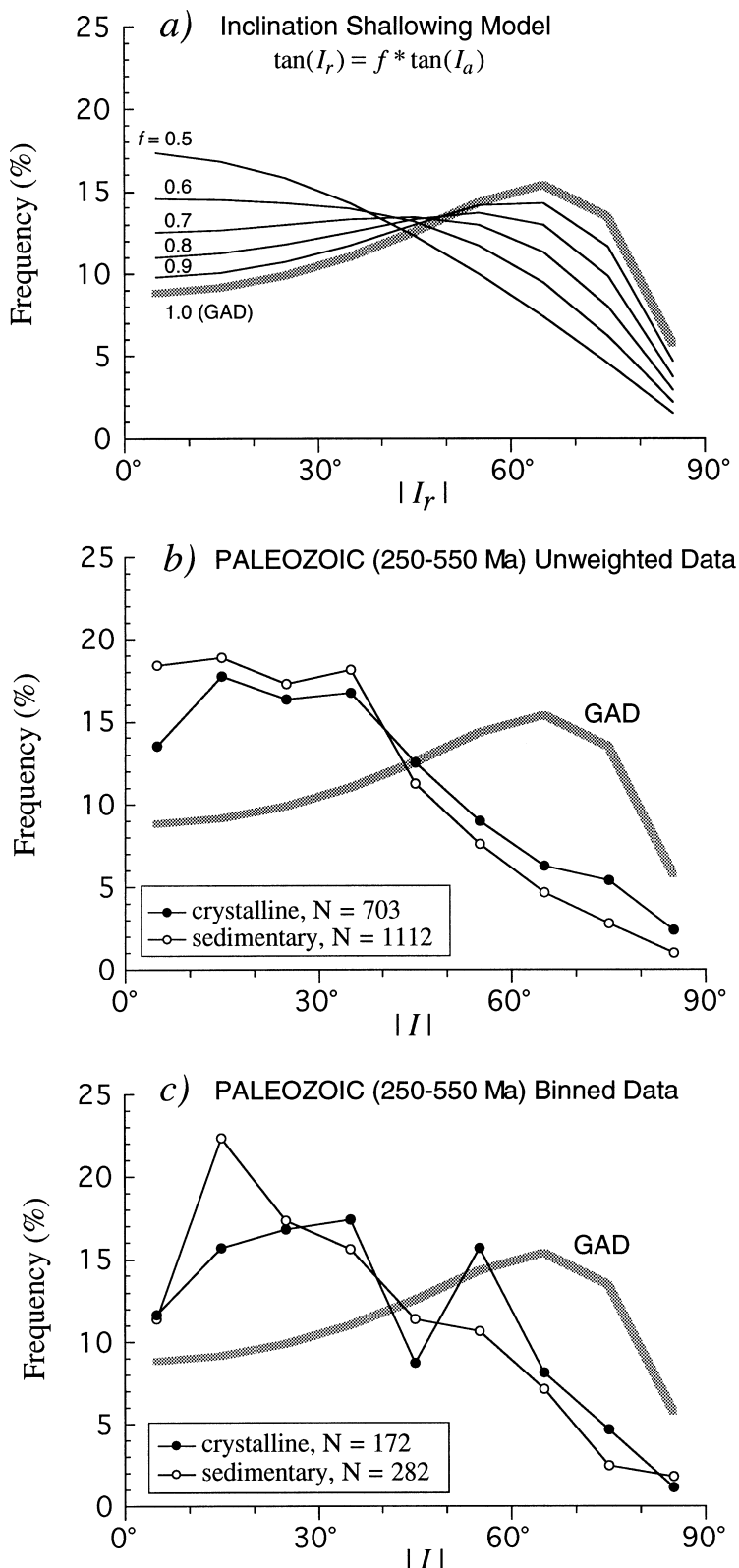

Fig. 3. (a) Theoretical $|I|$ distributions for representative values of sedimentary inclination error flattening factor, $f=0.5$ to 1.0 compared to predicted $|I|$ distribution for GAD where $f$ is effectively equal to 1 . (b) Comparison of $|I|$ distributions for Paleozoic paleomagnetic data from crystalline (igneous intrusive, igneous extrusive, and metamorphic) rocks versus sedimentary rocks for unweighted data. (c) Comparison of $|I|$ distributions for Paleozoic paleomagnetic data from crystalline (igneous intrusive, igneous extrusive, and metamorphic) rocks versus sedimentary rocks for binned data. 
that inclination flattening in sedimentary rocks is not a primary cause of the shift toward shallower inclinations that is apparent in the Paleozoic and Precambrian data sets. Although all other possible sources of secondary bias cannot be excluded categorically, we proceed to explore more fundamental causes for the apparent change in the observed $|I|$ distributions over geologic time.

\section{Zonal non-dipole field contributions}

The observational test described by Evans [21] was specifically designed to discriminate a dipole field from the fields of higher order zonal multipoles. Theoretical $|I|$ frequency distributions for pure quadrupole and octupole fields are increasingly flatter than the $|I|$ distribution for the dipole field (Fig. 4a) and clearly do not provide a better fit to any of the observed $|I|$ distributions. However, it does not necessarily follow that zonal field models more complex than a GAD are unable to explain anomalous $|I|$ distributions such as those observed for the Paleozoic or the Precambrian. In fact, plausible field models that include only modest quadrupolar and octupolar contributions to a dipole field can produce a surprisingly wide range of $|I|$ distributions.

Theoretical $|I|$ distributions corresponding to contributions of quadrupole relative to axial dipole fields (i.e., G2) ranging from -0.20 to +0.20 are shown in Fig. 4b. Over this range of $\mathrm{G} 2$ values, the $|I|$ distributions are not dependent on the sign and are not even very sensitive to the magnitude of the quadrupolar contribution. This is because the antisymmetry of the quadrupolar contribution results in a hemispheric compensation of steep and shallow inclinations when expressed as a histogram of absolute values sampled globally.

Theoretical $|I|$ distributions corresponding to various contributions of octupole relative to axial dipole fields (i.e., G3) are shown in Fig. 4c. In this case, the $|I|$ distributions are very sensitive to both the sign and the magnitude of the octupolar contribution. When $G 3$ is negative (i.e., the sign of the octupole field coefficient, $g_{3}^{0}$, differs from the sign of the dipole field coefficient, $g_{1}^{0}$ ), modest octupolar contributions cause inclinations to become generally steeper globally; this results in a $|I|$ distribution
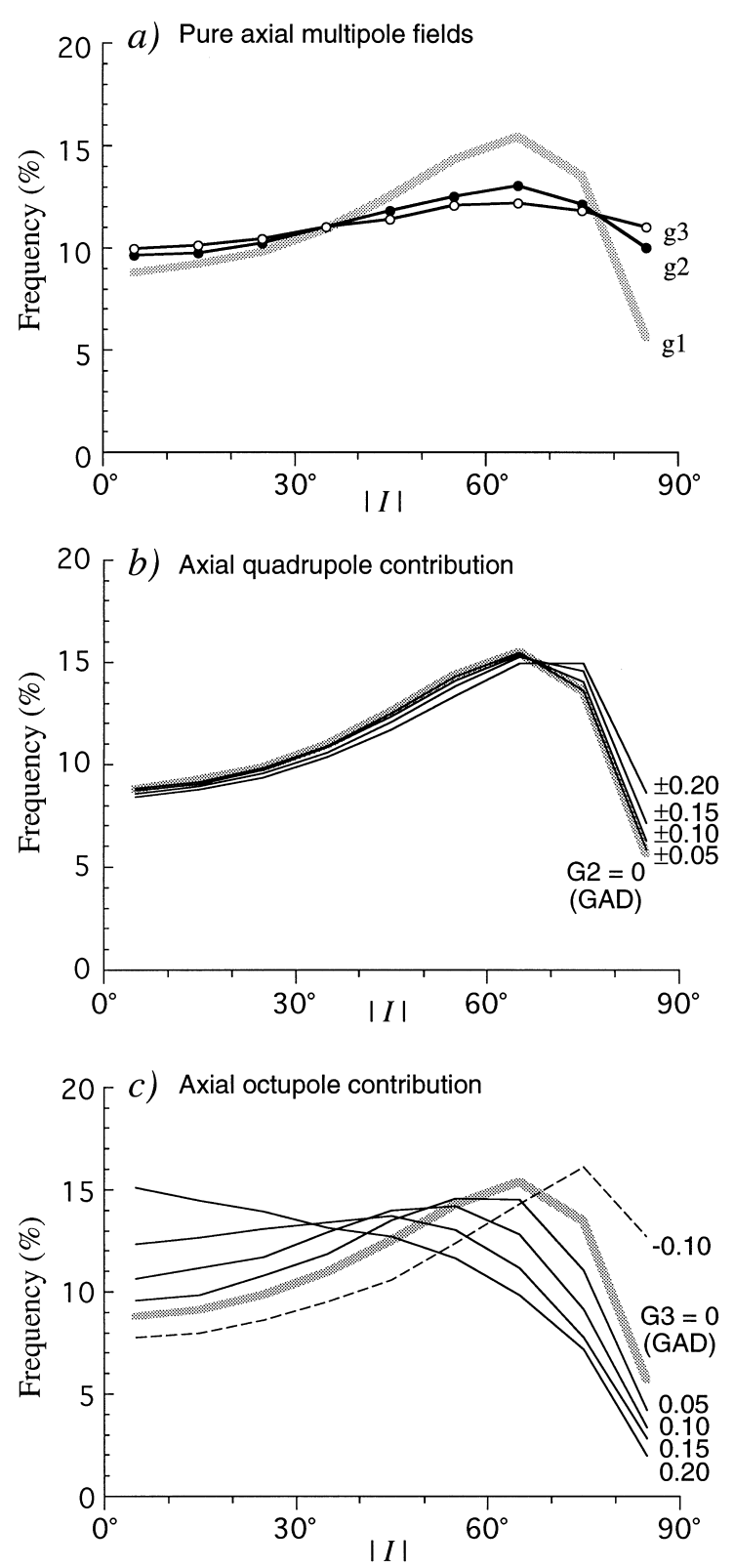

Fig. 4. Theoretical $|I|$ frequency distributions for different geomagnetic field models. (a) $|I|$ distributions for GAD (geocentric axial dipole), $g_{2}$ (pure zonal quadrupole) and $g_{3}$ (pure zonal octupole). (b) $|I|$ distributions for $G 2$ (ratio of zonal quadrupole to axial dipole) varying from 0 (i.e., GAD) to \pm 0.20 . Note that $|I|$ distribution is not sensitive to the sign of $G 2$. (c) $|I|$ distributions for $G 3$ (ratio of zonal octupole to axial dipole) varying from 0 (i.e., GAD) to +0.20 ; also shown is curve for $G 3=-0.10$ (dashed line) to illustrate sensitivity to the sign of $G 3$. 
skewed to steeper inclinations compared to the GAD model (Fig. 4c). This is not in the correct sense to fit the observations for the Paleozoic and Precambrian. However, when the octupole and dipole field coefficients have the same sign, and $G 3$ is therefore positive, modest octupolar contributions cause inclinations to become generally shallower globally. This results in $|I|$ distributions with greater frequencies at shallower inclinations with increasing octupole contribution so that a $G 3$ equal to about +0.2 produces a $|I|$ spectrum that begins to resemble the observed $|I|$ distributions for the Paleozoic and Precambrian (Fig. 4c).

We also examined $|I|$ distributions in the parameter space of modest quadrupolar plus octupolar contributions. Although the frequency distributions of $|I|$ are not very sensitive to $G 2$ alone (e.g., Fig. 4b), the introduction of a small quadrupolar contribution $(G 2= \pm 0.1)$ to octupolar contributions varying from $G 3=+0.05$ to $G 3=+0.30$ allows the development of a mode in the $|I|$ distribution at low inclination values (Fig. 5). Theoretical $|I|$ distributions resulting from a small quadrupolar contribution $(G 2 \sim \pm 0.1)$ and a somewhat larger octupolar contribution $(G 3 \sim+0.25)$ can provide a reasonable though certainly not a unique match to the observed Paleozoic and Precambrian distributions.

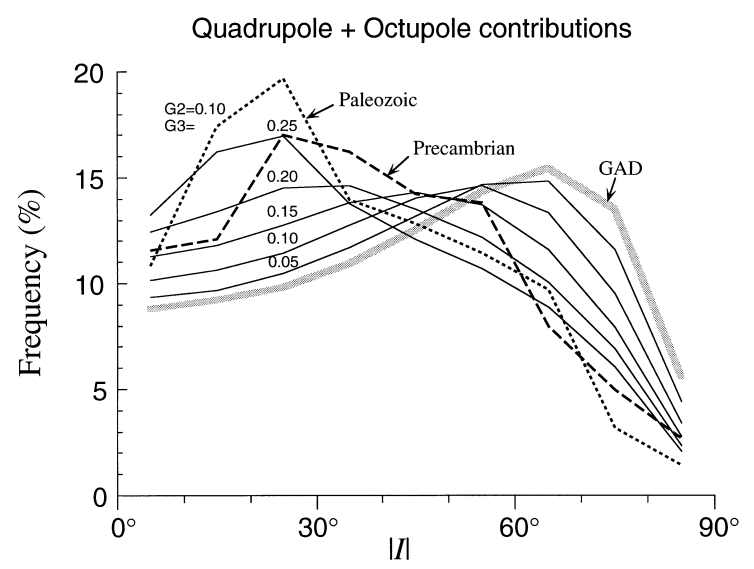

Fig. 5. Theoretical $|I|$ frequency distributions for geomagnetic field models with a fixed contribution to the axial dipole from a zonal quadrupole $(G 2=+0.10)$ and various contributions from a zonal octupole $(G 3=+0.05$ to +0.20$)$, compared to the anomalous $|I|$ distributions for the Paleozoic and Precambrian using binned data (see Fig. 2).

\section{Discussion}

To summarize the main observations, a comparison of predicted and observed $|I|$ distributions shows that the GAD hypothesis cannot be rejected for the Cenozoic and Mesozoic, whereas the $|I|$ frequency distributions for the Paleozoic and Precambrian are over-represented by low inclinations and are not compatible with a GAD field model. An underlying concern regarding the significance of these observations is that the paleomagnetic recording mechanism(s) may have systematic biases that are more prevalent in older rocks, for example, there may be a greater likelihood of compaction-induced inclination shallowing in older and more deeper buried sedimentary rocks. Although classical sedimentary inclination error can in principle produce $|I|$ distributions that have a similar pattern to the observed anomalous $|I|$ distributions for the Paleozoic and Precambrian, we see no convincing evidence for systematic differences in the observed inclinations that might then be expected according to major lithological types (i.e., sedimentary versus igneous and metamorphic). Some of the key sedimentary facies that are commonly studied for paleomagnetism, for example carbonates and redbeds, do not have global distributions but are more frequent in lower latitudes (e.g., [9]). The lack of obvious lithologic dependence of inclinations in the Paleozoic data would also argue that such a potential source of bias, as well as that resulting from hypothesized systematic remagnetizations where tropical weathering was thought to have caused widespread magnetic overprinting mainly of sediments in the late Paleozoic [35], may not be that important [24] in accounting for the anomalous Paleozoic $|I|$ distribution.

Our consideration of the possible effects of sampling or data artifacts in such a large and heterogeneous compilation like the global paleomagnetic data base is by no means exhaustive, but we have not been able to identify a convincing secondary mechanism to explain the anomalous $|I|$ distributions for the Paleozoic and the Precambrian amongst several obvious candidates. We therefore speculate that the anomalous $|I|$ distributions may have a more interesting and fundamental origin, related either to (1) a core dynamo that produced in its earlier history a time-averaged geomagnetic field that was different 
from the GAD configuration, or if a GAD model is assumed, (2) mantle processes that resulted in continents having a preference to be situated in lower latitudes.

The time-averaged geomagnetic field need not be radically different from a GAD configuration: a simple model suggests that an octupolar contribution of no more than about $25 \%$ and a quadrupolar contribution of about $10 \%$ relative to the axial dipole would be quite sufficient to account for the anomalous $|I|$ distributions for the Paleozoic and Precambrian (Fig. 5). This octupolar contribution or G3 is several times greater than the widely varying estimates of G3 for the 0-5 Ma time-averaged field (e.g., [2]), although the quadrupolar contribution or $G 2$ can be more comparable to Cenozoic estimates of typically $5 \%$ to $10 \%[2-5,36]$ to satisfy the Paleozoic and Precambrian data. The observed $|I|$ frequency distributions are thus compatible with a possible decrease in zonal NDF contributions to the GAD from more than about $25 \%$ in the Precambrian and Paleozoic to less than about $10 \%$ in Mesozoic and Cenozoic. If real, this long-term change in the overall geometry of the geomagnetic field could be linked to evolution of some boundary condition on the geodynamo; an intriguing albeit ad hoc possibility is growth of the solid inner core.

The fluid core most probably formed rapidly very early in Earth's history [37,38], consistent with paleomagnetic evidence of early geomagnetic field generation (e.g., [39]), but the timing of inner core formation and its expected paleomagnetic signature is very uncertain [40]. Recent thermal evolution models suggest that the inner core took anywhere from $1000 \mathrm{Ma}$ to $3600 \mathrm{Ma}$ to grow to its present size [20]; in other words, given $4600 \mathrm{Ma}$ as the age of the Earth, nucleation of the solid inner core may have begun in the Archean at about $3600 \mathrm{Ma}$ or not until the Neoproterozoic at about $1000 \mathrm{Ma}$. Stevenson et al. [41] suggested that the onset of compositional convection associated with the nucleation of the inner core would have significantly energized the geodynamo in the fluid outer core and produced a distinctive pattern of change in geomagnetic field strength; unfortunately, no consistent long-term variation is apparent according to recent assessments of the most reliable but still very incomplete paleointensity record from $3500 \mathrm{Ma}$ to present [42]. More recent numerical simulations have emphasized the critical role the inner core plays in the production of a stable magnetic field by the geodynamo $[18,19]$. Without the incorporation of a conducting inner core, most dynamo models generate rapidly oscillating or chaotic magnetic fields which apparently are damped owing to the long diffusive time constant of the inner core [43]. Indeed, Hollerbach and Jones [18,44] suggested that there is a critical threshold size of the inner core that is required for the operation of a stabilized geodynamo. If a time-averaged field configuration that more closely resembles a GAD model is speculatively considered a feature of a more stabilized geodynamo, then the apparent secular decrease in NDF contribution could be related to growth of the inner core. The young age of about $250 \mathrm{Ma}$ for the transition from an apparently larger to smaller NDF contribution would, however, imply either a large critical threshold size or very much delayed nucleation of the inner core.

An alternative explanation for the anomalous $|I|$ inclinations is that the time-averaged geomagnetic field in fact closely resembled a GAD model from Precambrian time onward but that the geographic distribution of data for the Paleozoic and Precambrian was for some reason biased to low latitudes. Piper and Grant [24] suggested, for example, that the concentration of continental crust in a single, polecentered supercontinent from about $1000 \mathrm{Ma}$ to 2800 Ma has biased the frequency of observed paleomagnetic inclinations in the Precambrian. Aside from the controversies surrounding the existence and specific configuration(s) of a Proterozoic supercontinent (e.g., $[14,45])$, it does not appear that a random geographical sampling of Piper's [12] pole-centered Proterozoic supercontinent reconstruction significantly improves upon a uniform global sampling model as an explanation for the non-GAD distribution of Precambrian inclinations [24]. Nevertheless, the possibility of a fundamental paleogeographic latitudinal bias underlying the paleomagnetic sampling in the Paleozoic and Precambrian cannot be excluded. In this regard, Anderson [46] has argued that large continental assemblies have major effects on the mantle and induce long-lived geoid highs (see also Ref. [47] for discussion of connections between the geoid and ancient plate boundaries). Since the body of the Earth will tumble with respect to the rota- 
tion axis in response to such mantle perturbations [48], long-lived continental aggregations associated with the geoid highs will also tend to migrate toward the Equator. The anomalous $|I|$ distributions for the Paleozoic and the Precambrian could therefore reflect a very long-term tendency of true polar wander to cycle continents into the equatorial belt. The long-lived continental aggregate that was being assembled over at least the latter part of the Precambrian would be Rodinia. When Rodinia is proposed to have undergone a protracted dismemberment from 750 to $600 \mathrm{Ma}$, continental elements with the most complete apparent polar wander paths (Laurentia, Baltica and Siberia) all drifted, apparently independently, from equatorial positions into intermediate to high southern latitudes [45]. The long-lived continental aggregate that was then being assembled in the Paleozoic was Pangea [6]. In contrast, most of the Mesozoic and the Cenozoic is marked by the dispersal of continents with a looser association with geoid anomalies, contributing to a more geographically random distribution as reflected in the more GAD-like $|I|$ frequency distributions.

\section{Conclusions}

Frequency distributions of $|I|$ from global paleomagnetic data are consistent with the GAD model of the time-averaged geomagnetic field for the Cenozoic and Mesozoic, or the past $250 \mathrm{Ma}$, but are skewed toward low inclinations and are thus anomalous with respect to expectations of a geographically random sample of a GAD field for the Paleozoic and Precambrian, or from about $250 \mathrm{Ma}$ to $3500 \mathrm{Ma}$, the practical age limit of paleomagnetic data.

After consideration of several obvious secondary sources of bias such as sedimentary inclination error, we suggest that the anomalous $|I|$ distributions for the Paleozoic and Precambrian have a more fundamental origin, due either to a modest but significant departure of the time-averaged geomagnetic field from a GAD model or to a geographical bias of the continents to low latitudes.

A simple model shows that NDF contributions to the GAD of about $25 \%$ from a zonal octupole and perhaps $10 \%$ from a zonal quadrupole could account for the anomalous $|I|$ distributions for the Paleozoic

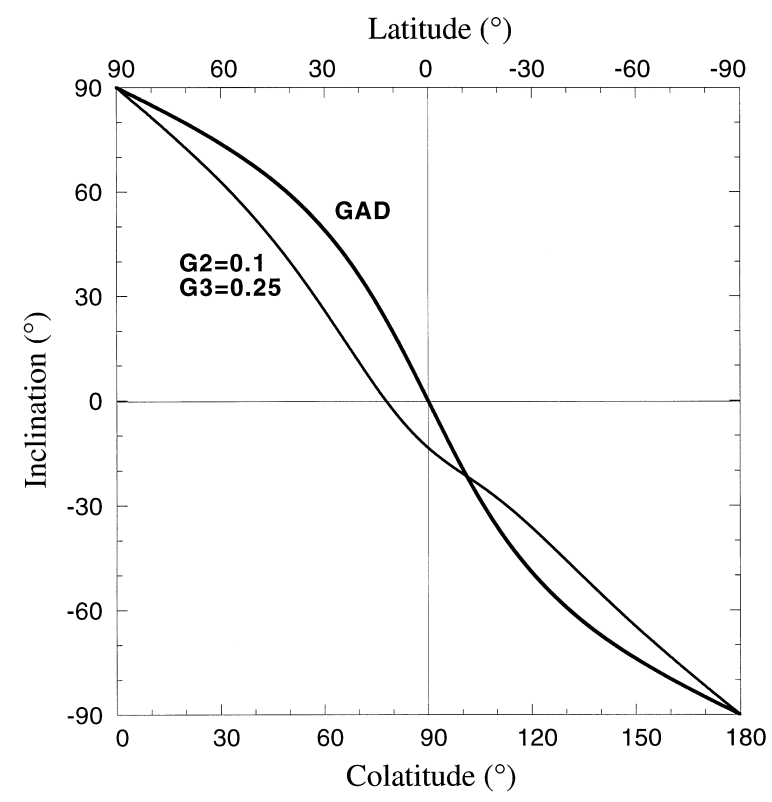

Fig. 6. Inclination as a function of colatitude for the GAD model compared to a model with contributions to the axial dipole from a zonal quadrupole $(G 2=0.10)$ plus a zonal octupole $(G 3=0.25)$. The curves are shown for normal polarity and would be reflected across an inclination of $0^{\circ}$ for reversed polarity. The GAD model of the time-averaged field is consistent with Cenozoic and Mesozoic paleomagnetic data. The particular NDF model shown $(G 2=0.1, G 3=0.25)$ better accounts for Paleozoic and Precambrian paleomagnetic data even though a standard GAD model is almost invariably used giving rise to potential errors in paleolatitude estimates according to the difference between the curves.

and Precambrian. If real, such a time-averaged field configuration would result in inclinations that may be up to about $25^{\circ}$ shallower compared to the GAD model; if used to calculate position with respect to the paleopole, the standard GAD formula would therefore tend to underestimate paleolatitudes by up to about $15^{\circ}$ in mid-latitude regions (Fig. 6).

The apparently diminishing NDF content of the time-averaged geomagnetic field from the Precambrian and Paleozoic to the Mesozoic and Cenozoic could be somehow related to a stabilizing effect on the geodynamo of a growing inner core [44], although we are not aware of any other evidence that supports or refutes such a speculation.

Alternatively, if the GAD model is assumed to be universally valid, the anomalous $|I|$ distributions for the Paleozoic and Precambrian can be interpreted 
as providing general support for the idea [46] that over very long time periods there is a tendency for continents to aggregate and migrate to low latitudes as the geoid anomalies they help to induce modulate true polar wander.

Statistical analysis of paleomagnetic inclination data may be one of the few observational methods available to assess fundamental questions about the configuration of the geomagnetic field or the geographic distribution of continents through geologic time. However, the overall quality of the database needs to be uniformly assessed (e.g., [49]) and continually improved by new data that meet modern standards to minimize the possibility of introducing artifacts resulting from poor data.

Other constraints will also be needed to differentiate the effects of geomagnetic (i.e., core-related) from paleogeographic (i.e., mantle-related) processes because interpretations of even the most robust $|I|$ anomalies are inherently non-unique. For example, further 3-D modeling of the geodynamo might eventually provide better theoretical support for the GAD hypothesis, whereas the delineation of long, well defined apparent polar wander paths for the various continental blocks might reveal systematic patterns compatible with episodes of true polar wander and equatorial cycling.

\section{Acknowledgements}

We thank Joe Meert, David Evans, and Rob Van der Voo for constructive comments on the paper in the review process. Part of this work was supported by the U.S. National Science Foundation. LamontDoherty Earth Observatory Contribution 5790. [RV]

\section{References}

[1] V. Courtillot, J.-P. Valet, G. Hulot, J.-L. Le Mouel, The Earth's magnetic field: which geometry?, Eos 73 (1992) 337-342.

[2] M.W. McElhinny, P.L. McFadden, R.T. Merrill, The timeaveraged paleomagnetic field 0-5 Ma, J. Geophys. Res. 101 (1996) 25007-25027.

[3] S.K. Runcorn, On the hypothesis that the mean geomagnetic field for parts of geological time has been that of a geocentric axial dipole, J. Atmos. Terrest. Phys. 14 (1959)
167-174.

[4] R.A. Livermore, F.J. Vine, A.G. Smith, Plate motions and the geomagnetic field: II, Jurassic to Tertiary, Geophys. J.R. Astron. Soc. 79 (1984) 939-961.

[5] D.A. Schneider, D.V. Kent, Testing models of the Tertiary paleomagnetic field, Earth Planet. Sci. Lett. 101 (1990) 260-271.

[6] R. Van der Voo, Paleomagnetism of the Atlantic, Tethys and Iapetus Oceans, Cambridge University Press, Cambridge, 1993, 411 pp.

[7] N.D. Opdyke, The impact of paleomagnetism on paleoclimatic studies, Int. J. Bioclimatol. Biometeorol. 3 (4A) (1959) 1-16.

[8] P.M.S. Blackett, Comparison of ancient climates with the ancient latitudes deduced from rock magnetic measurements, Proc. R. Soc. London A 263 (1961) 1-30.

[9] J.C. Briden, E. Irving, Palaeolatitude spectra of sedimentary palaeoclimatic indicators, in: A.E.M. Nairn (Ed.), Problems in Palaeoclimatology, Interscience, New York, 1964, pp. 199-250.

[10] C.R. Scotese, S.F. Barrett, Gondwana's movement over the South Pole during the Palaeozoic: evidence from lithological indicators of climate, in: W.S. McKerrow, C.R. Scotese (Eds.), Palaeozoic Palaeogeography and Biogeography, The Geological Society, London, 1990, pp. 75-85.

[11] A.G. Smith, Estimates of the Earth's spin (geographic) axis relative to Gondwana from glacial sediments and paleomagntism, Earth Sci. Rev. 42 (1997) 161-179.

[12] J.D.A. Piper, Proterozoic palaeomagnetism and single continent plate tectonics, Geophys. J. R. Astron. Soc. 74 (1983) 163-197.

[13] I.W.D. Dalziel, Earth before Pangea, Sci. Am. January 1995, pp. 58-63.

[14] T.H. Torsvik, M.A. Smethurst, J.G. Meert, R. Van der Voo, W.S. McKerrow, M.D. Brasier, B.A. Sturt, H.J. Walderhaug, Continental break-up and collision in the Neoproterozoic and Palaeozoic - a tale of Baltica and Laurentia, Earth Sci. Rev. 40 (1996) 229-258.

[15] J.G. Meert, R. Van der Voo, The Neoproterozoic (1000$540 \mathrm{Ma}$ ) glacial intervals: no more snowball earth?, Earth Planet. Sci. Lett. 123 (1994) 1-13.

[16] P.W. Schmidt, G.E. Williams, The Neoproterozoic climatic paradox: equatorial palaeolatitude for Marinoan glaciation near sea level in South Australia, Earth Planet. Sci. Lett. 134 (1995) 107-124.

[17] D.A. Evans, N.J. Beukes, J.L. Kirschvink, Low-latitude glaciation in the Palaeoproterozoic era, Nature 386 (1997) 262-266.

[18] R. Hollerbach, C.A. Jones, Influence of the Earth's inner core on geomagnetic fluctuations and reversals, Nature 365 (1993) 541-543.

[19] G.A. Glatzmaier, P.H. Roberts, A three-dimensional convective dynamo solution with rotating and finitely conducting inner core and mantle, Phys. Earth Planet. Inter. 91 (1995) 63-75.

[20] B.A. Buffett, H.E. Huppert, J.R. Lister, A.W. Woods, An- 
alytical model for solidification of the Earth's core, Nature 356 (1992) 329.

[21] M.E. Evans, Test of the dipolar nature of the geomagnetic field throughout Phanerozoic time, Nature 262 (1976) 676677.

[22] D.A. Schneider, D.V. Kent, The time-averaged paleomagnetic field, Rev. Geophys. 18 (1990) 71-96.

[23] M.W. McElhinny, J. Lock, IAGA paleomagnetic databases with access, Surv. Geophys. 17 (1996) 557-591.

[24] J.D.A. Piper, S. Grant, A palaeomagnetic test of the axial dipole assumption and implications for continental distribution through geological time, Phys. Earth Planet. Inter. 55 (1989) 37-53.

[25] B.J. Witzke, Palaeoclimatic constraints for Palaeozoic palaeolatitudes of Laurentia and Euramerica, in: W.S. McKerrow, C.R. Scotese (Eds.), Palaeozoic Palaeogeography and Biogeography, The Geological Society, London, 1990, pp. 57-73.

[26] M. Gurnis, T.H. Torsvik, Rapid drift of large continents during the late Precambrian and Paleozoic: paleomagnetic constraints and dynamic models, Geology 22 (1994) 1023 1026.

[27] R.F. King, The remanent magnetism of artificially deposited sediment, Mon. Not. R. Astron. Soc., Geophys. Suppl. 7 (1955) 115-134

[28] C.E. Barton, P.L. McFadden, Inclination shallowing and preferred transitional VGP paths, Earth Planet. Sci. Lett. 140 (1996) 147-157.

[29] L. Tauxe, Sedimentary records of relative paleointensity of the geomagnetic field: theory and practice, Rev. Geophys. 31 (1993) 319-354.

[30] P. Arason, S. Levi, Models of inclination shallowing during sediment compaction, J. Geophys. Res. 95 (1990) 44814499.

[31] G.A. Deamer, K.P. Kodama, Compaction-induced inclination shallowing in natural and clay-rich sediments, J. Geophys. Res. 95 (1990) 4511-4529.

[32] K.M. Creer, Systematic errors in the palaeomagnetic inclination of sedimentary rocks?, Nature 213 (1967) 482 485.

[33] E. Irving, Evidence for paleomagnetic inclination error in sediment, Nature 213 (1967) 483-484.

[34] R. Van der Voo, J. Stamatakos, B. van der Pluijm, No evidence for prevalent inclination shallowing in redbeds (abstr.), Eos (1995) S96.
[35] K.M. Creer, Palaeozoic palaeomagnetism, Nature 219 (1968) 246-250.

[36] D.H. Coupland, R. Van der Voo, Long-term non-dipole components in the geomagnetic field during the last 130 m.y., J. Geophys. Res. 84 (1980) 2519-3548.

[37] C.J. Allègre, B. Dupré, O. Brevart, Chemical aspects of the formation of the core, Philos. Trans. R. Soc. London A 306 (1982) 49.

[38] A. Halliday, M. Rehkamper, D.C. Lee, W. Yi, Early evolution of the Earth and Moon: new constraints from Hf-W isotope geochemistry, Earth Planet. Sci. Lett. 142 (1996) 75-89.

[39] M.W. McElhinny, W.E. Senanayake, Paleomagnetic evidence for the existence of the geomagnetic field $3.5 \mathrm{GA}$ ago, J. Geophys. Res. 85 (1980) 3523-3528.

[40] J.A. Jacobs, The Earth's inner core and the geodynamo: determining their roles in the Earth's history, Eos 76 (1995) 249-256.

[41] D.J. Stevenson, T. Spohn, G. Schubert, Magnetism and thermal evolution of the terrestrial planets, Icarus 54 (1983) 466-489.

[42] M. Prevot, M. Perrin, Intensity of the Earth's magnetic field since Precambrian from Thellier-type paleointensity data and inferences on the thermal history of the core, Geophys. J. Int. 108 (1992) 613-620.

[43] D. Gubbins, Influence of the inner core, Nature 365 (1993) 493.

[44] R. Hollerbach, C.A. Jones, On the magnetically stabilizing role of the Earth's inner core, Phys. Earth Planet. Inter. 87 (1995) 171-181.

[45] M.A. Smethurst, A.N. Khramov, T.H. Torsvik, The Neoproterozoic and Palaeozoic palaeomagnetic data for the Siberian Platform: from Rodinia to Pangea, Earth Sci. Rev. 43 (1998) $1-25$

[46] D.L. Anderson, Hotspots, polar wander, Mesozoic convection and the geoid, Nature 297 (1982) 391-393.

[47] C.G. Chase, D.R. Sprowl, The modern geoid and ancient plate boundaries, Earth Planet. Sci. Lett. 62 (1983) 314 320.

[48] P. Goldreich, A. Toomre, Some remarks on polar wandering, J. Geophys. Res. 74 (1969) 2555-2567.

[49] R. Van der Voo, Paleomagnetism of the Atlantic, Tethys and Iapetus Oceans, Cambridge University Press, Cambridge, 1993, 411 pp. 